\title{
LADA OR TYPE 2 DIABETES MELLITUS - A CHALLENGING DIAGNOSIS IN CLINICAL APPROACH
}

\author{
LUCIA MIHAELA CUSTURĂ ${ }^{1}$, OANA DETEȘAN ${ }^{2}$, RALUCA MARIA TILINCA ${ }^{3}$, \\ REKA ANNAMARIA SCHMIEDT ${ }^{4}$, BRIGITTA IRÉN BACSO ${ }^{5}$, MARIANA CORNELIA TILINCA ${ }^{6}$ \\ 1,2,4,5,6 Emergency Clinical County Hospital of Târgu-Mureș, \\ 3,6 “George Emil Palade” University of Medicine, Pharmacy, Science and Technology of Târgu-Mureș
}

\begin{abstract}
Keywords: diabetes Abstract: Latent autoimmune diabetes in adults (LADA) is a frequently encountered condition in mellitus, LADA, glutamic medical practice. It should be suspected in patients where the type of the diabetes mellitus is not acid decarboxylase, $c$ - certain. LADA consists of features from both type 1 diabetes mellitus (T1DM) and type 2 diabetes peptide mellitus (T2DM), being a condition which is often unnoticed. Considered as type 1.5 diabetes mellitus, the lack of insulin requirement at disease onset makes it initially to be included in T2DM in terms of therapeutic management. The improvement of the screening methods allows the detection of LADA at an early stage, therefore medical intervention should be effective in preserving beta-cell function and to delay the progression of the disease.
\end{abstract}

\section{INTRODUCTION}

Diabetes mellitus (DM) is a complex disease, the current classification includes type 1 diabetes mellitus (T1DM), type 2 diabetes mellitus (T2DM), secondary diabetes mellitus and gestational diabetes mellitus. Latent autoimmune diabetes in adults (LADA), is characterised by an autoimmune and genetic process similar to T1DM, which occurs in adulthood $(>30$ years). The similarity to T2DM is the lack of insulin requirements at the onset of the disease. $(1,2)$

LADA, referred to by some authors as diabetes mellitus type 1.5 , has clinical and biological features of both T1DM and T2DM, being a borderline diagnosis. LADA is included by American Diabetes Association in T1DM, classified as autoimmune diabetes with a slower progression to insulinopenia, not being a particular type of DM.(3) Because of the similarity to T2DM at onset, the therapeutic management, according to current guidelines, is the same. World Health Organisation does not recognise LADA as a stand-alone diagnosis, referred to as slowly evolving, immune-related diabetes, currently included in the T1DM classification.(4) The term used for LADA in Japan is slowly progressive insulindependent type 1 diabetes mellitus (SPIDDM).(5)

Epidemiology of LADA

The incidence of LADA in diabetic patients varies between $2-12 \%$, taking into account ethnicity and screening criteria such as measuring glutamic acid decarboxylase autoantibody (GADA) or islet cell autoantibodies (ICA) used in different countries. Recent studies show that $3 \%$ to $12 \%$ of patients initially diagnosed with T2DM have autoantibodies, thus resulting in the shifting paradigm of LADA diagnosis. $(6,7)$

Pathophysiology and genetics of LADA

The LADA pathophysiology is not fully clarified, the patients have the T1DM genotype and the intermediate phenotype of both T1DM and T2DM.(8) Regarding the process of pancreatic beta-cell self-destruction in LADA, partial or slowly progressive alteration of the pancreatic reserve (approximately two-thirds) is observed, compared to total destruction in T1DM.(9)

C-peptide levels reflect the insulin secretion and the pancreatic reserve at the time of DM diagnosis.

Genetic susceptibility is a topic still under investigation. LADA is associated with genes that encode human leukocyte antigen (HLA), cytotoxic $\mathrm{T}$ lymphocyte antigen 4 (CTLA4), tyrosine-protein phosphatase non-receptor type 22 (PTPN22) and insulin. $(10,11,12)$

The highest risk for LADA represents the association with the DRB1 0301 and DRB1 0401 genes. Also, DRB1 0401 and DQB1 0302 genotypes were associated with younger age at diagnosis and DRB1 1501 and DQB1 0602 with older age at diagnosis of LADA. $(13,14)$ The autoimmune process involved in the development of the disease is evidenced by assay of autoantibody levels. The most important parameters in confirming the diagnosis are GADA and autoantibodies to the tyrosine phosphatases (IA-2A), but also insulin autoantibodies (IAA), zinc transporter 8 (ZnT8), and tetraspanin 7. GADA is the most specific marker in LADA screening, accounting for $94-$ $99 \%$ of cases. $(15,16)$

Detection of glutamic acid decarboxylase 65 antibodies (anti-GAD65) by electrochemiluminescence assay facilitates the subclassification of LADA into two types: one without antibodies more similar to T2DM and one with positive antibodies more similar to T1DM.(17)

A high level of GADA is associated with a higher insulin requirement.(1) IA-2A, on the other hand, are present in this category of patients, with a lower sensitivity and specificity of $40-97 \%$.(18)

Risk factors and diagnosis of LADA

Risk factors include obesity, sedentary lifestyle, smoking, low birth weight, consumption of processed red meat, sweetened beverages and coffee. Fish fat and moderate alcohol consumption may have a protective effect.(19-22) Also, family history of DM may determine LADA resemblance more to

${ }^{2}$ Corresponding author: Oana Deteșan, Str. Gh. Marinescu, Nr. 50, Cod 540136, Târgu-Mureș, România, E-mail: oana90oana@yahoo.com, Phone: +40741 281949

Article received on 04.08.2021 and accepted for publication on 02.09.2021

AMT, vol. 26, no. 3, 2021, p. 55 


\section{CLINICAL ASPECTS}

T1DM or T2DM.(23)

Clinical presentation in LADA is less specific than T1DM and T2DM. The onset of the disease can range from insidious, without pathognomonic signs and symptoms, to acute manifestation of diabetic ketoacidosis. This broad spectrum is directly related to the degree of beta-cell destruction; a noisier onset may be an indicator of marked pancreatic destruction. $(3,24)$

A diagnosis of LADA can be considered in patients with the disease onset over 30 years of age, the presence of diabetes-associated autoantibodies (GADA, ICA) and the absence of insulin requirement within the first 6 months of onset.(1) Detection of anti-pancreatic antibodies, GADA and ICA, are considered predictor factors of insulin dependence.(25)

LADA is a mixed entity, at the border between T1DM and T2DM, sharing clinical and metabolic criteria on both sides, as mentioned in several studies (table no. 1).(3,10)

Table no. 1. Clinical and metabolic features between T1DM, LADA and T2DM

\begin{tabular}{|c|c|c|c|}
\hline Main features & T1DM & LADA & T2DM \\
\hline Age onset & $\begin{array}{ll}\begin{array}{l}\text { Childhood } \\
\text { adolescence } \\
\text { (rarely }\end{array} & \text { at } \\
\text { adulthood) } & \\
\end{array}$ & $>30$ years & $\begin{array}{l}\text { Adulthood } \\
\text { (rarely before) }\end{array}$ \\
\hline $\begin{array}{l}\text { Family history } \\
\text { of diabetes }\end{array}$ & Variable & Variable & Often positive \\
\hline $\begin{array}{l}\text { HLA } \\
\text { susceptibility }\end{array}$ & Increased & Increased & Mild increased \\
\hline $\begin{array}{l}\text { Body mass } \\
\text { index (BMI) }\end{array}$ & Normal & Normal & $\begin{array}{l}\text { Overweight } \\
\text { obesity }\end{array}$ \\
\hline Clinical onset & $\begin{array}{l}\text { Acute } \\
\text { (frequently } \\
\text { ketoacidosis) }\end{array}$ & $\begin{array}{l}\text { Silent or } \\
\text { subclinical }\end{array}$ & $\begin{array}{ll}\text { Silent } & \text { or } \\
\text { subclinical } & \end{array}$ \\
\hline Autoantibodies & Increased & $\begin{array}{l}\text { Mild } \\
\text { increased }\end{array}$ & Absent \\
\hline $\begin{array}{l}\text { C-peptide } \\
\text { levels at onset }\end{array}$ & $\begin{array}{l}\text { Decreased or } \\
\text { non-detectable }\end{array}$ & Detectable & $\begin{array}{ll}\text { Normal } & \text { or } \\
\text { increased } & \end{array}$ \\
\hline $\begin{array}{l}\text { Insulin } \\
\text { resistance }\end{array}$ & Mild & Variable & Increased \\
\hline $\begin{array}{l}\text { Insulin } \\
\text { treatment }\end{array}$ & At onset & $\begin{array}{l}>6 \text { months } \\
\text { after onset }\end{array}$ & $\begin{array}{l}\text { Absent or years } \\
\text { after onset }\end{array}$ \\
\hline $\begin{array}{l}\text { Long-term } \\
\text { complications } \\
\text { at diagnosis }\end{array}$ & Rare & Rare & Frequent \\
\hline $\begin{array}{l}\text { Cardiovascular } \\
\text { risk }\end{array}$ & Increased & Increased & Increased \\
\hline Lipid profile & Normal & $\begin{array}{l}\text { Normal or } \\
\text { hypertriglyc } \\
\text { eridemia }\end{array}$ & Dyslipidemia \\
\hline
\end{tabular}

Screening of patients with LADA can be facilitated by using a risk score with a sensitivity of $90 \%$ and specificity of $71 \%$. This includes: age at onset below 50 years, symptomatic hyperglycemia, body mass index (BMI) below $25 \mathrm{~kg} / \mathrm{m} 2$ and personal or family history of autoimmune disease. Two of these criteria are required for diagnosis.(26)

When faced with a newly diagnosed diabetic patient, the first issue is to establish the etiological diagnosis. The current algorithm is to assay for GADA and C-peptide level, which helps in clinical practice to exclude T2DM. However, if the suspicion of LADA remains, with negative GADA, other less specific autoantibodies may be recommended to be identified, such as ICA, IA-2A, ZnT8. The presence of autoantibodies and a normal or low C-peptide level divides therapeutic management into two possibilities. A C-peptide level below $0.3 \mathrm{nmol} / \mathrm{L}$ requires initiation of insulin therapy. When C-peptide values are between 0.3-0.7 nmol/L metformin can be initiated and the patient should be reassessed at 6 months.(1)
Between LADA and T2DM, metabolic dysfunctions such as dyslipidemia is more noticeable in the second one, as well as metabolic syndrome, higher BMI and increased insulin resistance. $(27,28,29)$ Homeostatic model assessment for insulin resistance (HOMA-IR) is lower in LADA than T2DM and increases proportionally with BMI value.(1)

The differentiation between LADA and T2DM on long-term is an active screening based on the determination of diabetes-associated autoantibody levels. Although this appears to be a reliable method of differential diagnosis, it cannot be used in daily clinical practice due to high costs.

Therapeutic management of LADA

Due to the phenotypic similarity of LADA with T2DM, these two are often confused; for this reason, the initiation of oral glucose-lowering therapy comes as a normal step in clinical approach. The differentiation between the two, in the absence of active screening, is made only by time, through lack of achieving glycemic control and the need to initiate insulin therapy.

Active follow-up and reassessment of diabetes cases where LADA is suspected represents the cornerstone of rapid screening and preservation of long-term beta-cell function.

An individualized approach of the patients is necessary, with the choice of the optimal pharmacologic regimen being an important challenge to achieve target glycemic values and good metabolic control.

$\mathrm{C}$-peptide values below $0.3 \mathrm{nmol} / \mathrm{L}$ require initiation of prandial, basal or combination of both insulin therapies.(1)

C-peptide values between 0.3-0.7 nmol/L may allow the use of metformin with reassessment at 6 months. Metformin is preferable in obese patients with insulin resistance in whom diet does not achieve target glycemic values. $(1,26)$

It is recommended to be avoided the sulfonylureas in non-insulin therapy. These glucose-lowering drugs may promote insulin depletion simultaneously with C-peptide depletion, with exacerbation of autoimmunity and a much faster progression to insulin therapy.(30) Nowadays, the modern pharmacological techniques target the most efficient procedures in order to obtain the best clinical results. However, there are modified released (MR) formula for some antidiabetic drugs, like gliclazide MR, which have as aim the preservation of the pancreatic beta-cells and this could be a future focus in the management of LADA.(31-34)

The thiazolidinediones (TZD) increase insulin sensitivity, preserve beta-cell function and maintain long-term C-peptide concentration.

Dipeptidyl peptidase 4 inhibitors (DPP-4i) also lead to protection of beta-cell function, by blocking the destruction of glucagon-like peptide-1 (GLP-1). Recent studies have demonstrated additional benefits in preserving pancreatic function by combining saxagliptin with $2000 \mathrm{IU} /$ day of vitamin D3. $(35,36)$ Glucagon-like peptide-1 receptor agonists (GLP-1 RA) and sodium-glucose cotransporter 2 inhibitors (SGLT2i) can also be used in LADA therapy. It should be noted that the treatment with SGLT2i requires caution because of the diabetic ketoacidosis risk especially in patients with BMI below 27 $\mathrm{kg} / \mathrm{m} 2 .(1,37,38)$

As regards GLP-1 RA, dulaglutide has shown effectiveness on reducing the glycosylated hemoglobin (HbA1C) levels in one-year follow-up, thus improving metabolic control.(39)

In choosing the optimal treatment, the parameter that guides therapeutic management is the $\mathrm{HbA1C}$ value. Taking in consideration the $\mathrm{HbA} 1 \mathrm{C}$ value, cardiovascular and renal risk of LADA patients it is recommended the addition of the abovementioned drug classes to the therapy regimen. The aim of this association is to achieve and maintain $\mathrm{HbA1C}$ level within 


\section{CLINICAL ASPECTS}

target values.

Immunomodulatory therapy with autoantigen administration or lymphocyte receptor blockade can also be mentioned as another therapeutic approach, but safety studies are currently limited.(40)

Future perspectives in LADA management

The diagnosis of LADA is a professional challenge for specialist physicians, as consequence of the patient features considered at borderline between T1DM and T2DM.

Comparing LADA with T2DM in terms of disease progression and prognosis, LADA has a lower mortality and risk for any future cardiovascular events such as acute myocardial infarction, heart failure, stroke.(41) Nevertheless, because of the time period elapsed between the onset of the disease and the diagnosis of LADA, studies show a higher severity of diabetic neuropathy progression in patients with LADA compared to T2DM. $(42,43)$

Proper LADA screening and diagnosis along with lifestyle changes can bring major benefits to a patient's quality of life. $(44,45,46)$

The development of a therapeutic management guideline is necessary for a complete medical approach.

\section{CONCLUSIONS}

LADA is an autoimmune disease that falls within the spectrum of adult-onset diabetes mellitus. The diagnosis of this condition is overlooked in clinical practice due to laborious and costly investigations. LADA, despite the presence of autoantibodies, which are not routinely performed, is misdiagnosed as T2DM, because of the similar phenotype.

In most cases, the diagnosis of LADA involves the clinical judgment of the specialist physician and in borderline cases, must presume LADA and investigate further accordingly. Regarding therapeutic management, progression to insulin therapy is slower, therefore antidiabetic drugs that preserve betacell function are preferred.

Active screening of C-peptide levels and autoantibodies with the involvement of the specialist physician helps in detecting LADA at an early stage. Thus, achieving the two main goals in management, such as preserving beta-cell function and improving metabolic control, can improve quality of life and reduce long-term complications. Further studies are necessary to develop a therapeutic approach that leads to early detection of LADA in those patients where the type of DM diagnosis is uncertain.

\section{REFERENCES}

1. Buzzetti R, Tuomi T, Mauricio D, Pietropaolo M, Zhou Z, Pozzilli $\mathrm{P}$ et al. Management of Latent Autoimmune Diabetes in Adults: A Consensus Statement from an International Expert Panel. Diabetes. 2020;69(10):20372047.

2. Hernández M, Mauricio D. Latent Autoimmune Diabetes in Adults: A Review of Clinically Relevant Issues. Advances in Experimental Medicine and Biology; 2020. p. 29-41.

3. Pieralice S, Pozzilli P. Latent Autoimmune Diabetes in Adults: A Review on Clinical Implications and Management. Diabetes Metab J. 2018;42(6):451-464.

4. Classification of diabetes mellitus. Geneva: World Health Organization; 2019.

5. Nishimura A, Matsumura K, Kikuno S, et al. Slowly Progressive Type 1 Diabetes Mellitus: Current Knowledge And Future Perspectives. Diabetes Metab Syndr Obes. 2019;12:2461-2477.

6. Naik R, Brooks-Worrell B, Palmer J. Latent Autoimmune Diabetes in Adults. The Journal of Clinical Endocrinology \& Metabolism. 2009;94(12):4635-4644.
7. Zinman B, Kahn S, Haffner S, O'Neill M, Heise M, Freed M. Phenotypic Characteristics of GAD Antibody-Positive Recently Diagnosed Patients With Type 2 Diabetes in North America and Europe. Diabetes. 2004;53(12):31933200 .

8. Andersen M. New Insights into the Genetics of Latent Autoimmune Diabetes in Adults. Current Diabetes Reports. 2020;20(9).

9. Jörns A, Wedekind D, Jähne J, Lenzen S. Pancreas pathology of latent autoimmune diabetes in adults (LADA) in patients and in a LADA rat model compared with type 1 diabetes. Diabetes. 2020;69:624-633.

10. Buzzetti R, Zampetti S, Maddaloni E. Adult-onset autoimmune diabetes: current knowledge and implications for management. Nature Reviews Endocrinology. 2017;13(11):674-686.

11. Chen W, Chen X, Zhang M, Huang Z. The association of human leukocyte antigen class II (HLA II) haplotypes with the risk of Latent autoimmune diabetes of adults (LADA): Evidence based on available data. Gene. 2021;767:145177.

12. Laugesen E, Østergaard JA, Leslie RD; Danish Diabetes Academy Workshop and Workshop Speakers. Latent autoimmune diabetes of the adult: current knowledge and uncertainty. Diabet Med. 2015 Jul;32(7):843-852.

13. Desai M, Zeggini E, Horton V, Owen K, Hattersley A, Levy $\mathrm{J}$ et al. An association analysis of the HLA gene region in latent autoimmune diabetes in adults. Diabetologia. 2006;50(1):68-73.

14. Maddaloni E, Moretti C, Mignogna C, Buzzetti R. Adultonset autoimmune diabetes in 2020: An update. Maturitas. $2020 \mathrm{Jul} ; 137: 37-44$.

15. Hawa M, Kolb H, Schloot N, Beyan H, Paschou S, Buzzetti $\mathrm{R}$ et al. Adult-Onset Autoimmune Diabetes in Europe Is Prevalent With a Broad Clinical Phenotype: Action LADA 7. Diabetes Care. 2012;36(4):908-913.

16. Lampasona V, Pittman DL, Williams AJ, et al. Islet Autoantibody Standardization Program 2018 Workshop: Interlaboratory Comparison of Glutamic Acid Decarboxylase Autoantibody Assay Performance. Clin Chem. 2019;65(9):1141-1152.

17. Zhu Y, Qian L, Liu Q, et al. Glutamic Acid Decarboxylase Autoantibody Detection by Electrochemiluminescence Assay Identifies Latent Autoimmune Diabetes in Adults with Poor Islet Function. Diabetes Metab J. 2020;44(2):260-266.

18. Tiberti C, Giordano C, Locatelli M, Bosi E, Bottazzo G, Buzzetti $\mathrm{R}$ et al. Identification of Tyrosine Phosphatase 2(256-760) Construct as a New, Sensitive Marker for the Detection of Islet Autoimmunity in Type 2 Diabetic Patients: The Non-Insulin Requiring Autoimmune Diabetes (NIRAD) Study 2. Diabetes. 2008;57(5):1276-1283.

19. Li XH, Yu FF, Zhou YH, He J. Association between alcohol consumption and the risk of incident type 2 diabetes: A systematic review and dose-response metaanalysis. Am J Clin Nutr. 2016;103(3):818-829.

20. Carlsson S. Environmental (Lifestyle) Risk Factors for LADA. Current Diabetes Reviews. 2019;15(3):178-187.

21. Hjort R, Ahlqvist E, Carlsson PO, et al. Overweight, obesity and the risk of LADA: results from a Swedish casecontrol study and the Norwegian HUNT Study. Diabetologia. 2018;61(6):1333-1343.

22. Löfvenborg JE, Ahlqvist E, Alfredsson L, Andersson T, Groop L, Tuomi T, Wolk A, Carlsson S. Consumption of red meat, genetic susceptibility, and risk of LADA and type 2 diabetes. Eur J Nutr. 2021 Mar;60(2):769-779.

23. Hjort R, Alfredsson L, Andersson T, et al. Family history of type 1 and type 2 diabetes and risk of latent autoimmune 


\section{CLINICAL ASPECTS}

diabetes in adults (LADA). Diabetes Metab. 2017;43(6):536-542.

24. Banerjee P, Khan NZ, Singh ST, Singh N, Qamar I. Latent autoimmune diabetes in adults: complication, management and treatment modalities. Endocrinol Metab Int J.2019;7(3):67-72.

25. Zaharia OP, Bobrov P, Strassburger K, et al. Metabolic Characteristics of Recently Diagnosed Adult-Onset Autoimmune Diabetes Mellitus. J Clin Endocrinol Metab. 2018;103(2):429-437.

26. Rajkumar V, Levine SN. Latent Autoimmune Diabetes. In: StatPearls. Treasure Island (FL): StatPearls Publishing; July $18 ; 2021$

27. Fadiga L, Saraiva J, Catarino D, Frade J, Melo M, Paiva I. Adult-onset autoimmune diabetes: comparative analysis of classical and latent presentation. Diabetol Metab Syndr. 2020;12(1):107.

28. Mishra R, Hodge KM, Cousminer DL, Leslie RD, Grant SFA. A Global Perspective of Latent Autoimmune Diabetes in Adults. Trends Endocrinol Metab. 2018;29(9):638-650.

29. Castelblanco E, Hernández M, Castelblanco A, et al. Lowgrade Inflammatory Marker Profile May Help to Differentiate Patients With LADA, Classic Adult-Onset Type 1 Diabetes, and Type 2 Diabetes. Diabetes Care. 2018;41(4):862-868.

30. Koufakis T, Katsiki N, Zebekakis P, Dimitriadis G, Kotsa $\mathrm{K}$. Therapeutic approaches for latent autoimmune diabetes in adults: One size does not fit all. J Diabetes. 2020;12(2):110-118.

31. Gribble FM, Ashcroft FM. Differential sensitivity of betacell and extrapancreatic KATP channels to gliclazide. Diabetologia. 1999;42:845-848.

32. Engler RL, Yellon DM. Sulfonylurea KATP Blockade in Type II Diabetes and Preconditioning in Cardiovascular Disease. Circulation. 1996;94:2297-2301.

33. Heller SR; ADVANCE Collaborative Group. A summary of the ADVANCE Trial. Diabetes Care. 2009;32 Suppl 2(Suppl 2):S357-S361.

34. Avogaro A. Treating diabetes today with gliclazide MR: a matter of numbers. Diabetes Obes Metab. 2012 Jan;14 Suppl 1:14-19.

35. Zhang $\mathrm{Z}$, Yan $\mathrm{X}, \mathrm{Wu} \mathrm{C}$, et al. Adding vitamin D3 to the dipeptidyl peptidase-4 inhibitor saxagliptin has the potential to protect $\beta$-cell function in LADA patients: A 1year pilot study. Diabetes Metab Res Rev. 2020;36(5):e3298.

36. Pinheiro MM, Pinheiro FMM, Diniz SN, Fabbri A, Infante M. Combination of vitamin D and dipeptidyl peptidase-4 inhibitors (VIDPP-4i) as an immunomodulation therapy for autoimmune diabetes. Int Immunopharmacol. 2021;95:107518.

37. Latif A, Gastelum AA, Sood A, Reddy JT. Euglycaemic diabetic ketoacidosis in a 43-year-old woman with type 2 diabetes mellitus on SGLT-2 inhibitor (empagliflozin). BMJ Case Rep. 2020;13(6):e235117.

38. White-Cotsmire AJ, Healy AM. Ketogenic Diet as a Trigger for Diabetic Ketoacidosis in a Misdiagnosis of Diabetes: A Case Report. Clin Diabetes. 2020;38(3):318321.

39. Pozzilli P, Leslie RD, Peters AL, et al. Dulaglutide treatment results in effective glycaemic control in latent autoimmune diabetes in adults (LADA): A post-hoc analysis of the AWARD-2, -4 and -5 Trials. Diabetes Obes Metab. 2018;20(6):1490-1498.

40. Liu B, Xiang Y, Liu Z, Zhou Z. Past, present and future of latent autoimmune diabetes in adults. Diabetes Metab Res
Rev. 2020;36(1):e3205.

41. Wod M, Thomsen RW, Pedersen L, Yderstraede KB, BeckNielsen H, Højlund K. Lower mortality and cardiovascular event rates in patients with Latent Autoimmune Diabetes In Adults (LADA) as compared with type 2 diabetes and insulin deficient diabetes: A cohort study of 4368 patients. Diabetes Res Clin Pract. 2018;139:107-113.

42. Issar T, Yan A, Kwai NCG, et al. Altered peripheral nerve structure and function in latent autoimmune diabetes in adults. Diabetes Metab Res Rev. 2020;36(3):e3260.

43. Alam U, Jeziorska M, Petropoulos IN, et al. Latent autoimmune diabetes of adulthood (LADA) is associated with small fibre neuropathy. Diabet Med. 2019;36(9):11181124.

44. Carlsson S. Etiology and Pathogenesis of Latent Autoimmune Diabetes in Adults (LADA) Compared to Type 2 Diabetes. Front Physiol. 2019;10:320.

45. Frazier AR. Correct Diabetes Diagnosis and Treatment Allows Sailor to Remain on Active Duty. Mil Med. 2020;185(9-10):e1843-e1846.

46. O'Neal KS, Johnson JL, Panak RL. Recognizing and Appropriately Treating Latent Autoimmune Diabetes in Adults. Diabetes Spectr. 2016; 29(4):249-252. 